Original Article

\title{
Curriculum Development in Higher Education - from Theory to Practice at VNU University of Education in the Context of University Autonomy Implementation
}

\author{
Duong Thi Hoang Yen*, Nguyen Phuong Huyen, \\ Nguyen Thi Thanh Ly, Nghiem Thi Duong \\ VNU University of Education, 144 Xuan Thuy, Cau Giay, Hanoi, Vietnam \\ Received 26 September 2019 \\ Revised 28 October 2019; Accepted 28 October 2019
}

\begin{abstract}
In the trend of innovation and autonomy in higher education, curriculum development plays an important role for each university to affirm its quality and position. This paper argues that a new meaning for undergraduate curriculum must be developed to reflect the University's autonomy and ensure its efficiency. This requires renewed discussion of all aspects of curriculum in higher education, from theory to practice. This paper also discusses the result of a study on the curriculum development in the University of Education (UED) - a member university of Vietnam National University, Hanoi (VNU), assesses the degree of autonomy and effectiveness of the curriculum as well as proposes solutions to ensure the quality of training, realizing the vision and mission of the University.
\end{abstract}

Keywords: Curriculum, curriculum development, autonomy in higher education.

\section{Introduction}

In the context of international integration and accelerating the quality of training to meet the requirements of the industrial revolution 4.0, higher education in Vietnam has changed significantly. The increased autonomy associated with accountability for training quality has put higher education institutions

\footnotetext{
${ }^{*}$ Corresponding author.

E-mail address: huyennp2526@gmail.com

https://doi.org/10.25073/2588-1159/vnuer.4309
}

under a pressure of change, including curriculum development to bring higher education keep up with the times.

Early identify the significance of curriculum development for training quality and university rankings, Hanoi National University frequently concerned about this issue both as a policy construct and a practical process. As a member unit of Hanoi National University, the study of the status of curriculum development in the context of autonomy implementation at the University of Education, from which there are specific proposals contributing to improving the 
quality of training in general, which are very important and urgent. For this reason, two questions framed the research:

1. What is the nature of curriculum in higher education both as theory and a practical process?

2. How does curriculum development work in practice in University of Education?

\section{Theoretical approach to curriculum development in the context of university autonomy}

A curriculum is considered the "heart" of any learning institution which means that universities cannot exist without a curriculum. With its importance in formal education, the curriculum has become a dynamic process due to the changes that occur in our society. The term "curriculum" began to appear in 1820 , but it was not until the nineteenth century that the term was commonly used in the educational field in the United States and some countries with developed education. According to Pratt (1994, p.5) and Barrow [1]. The word curriculum is from the Latin currere, meaning "a course to be run, or the running of the course," and usually is defined as the course of study at an educational institution. William Pinar (1975) argues that currere, as the Latin infinitive suggests "the traditional definition of curriculum is Course of Study" [2].

Bobbitt (1924) defined the curriculum in two directions [3]:

(i) It is a series of activities designed to detect the ability of each learner.

(ii) It is a series of activities intended to improve the learner's capabilities.

Going in this direction, in 1935, Hollis and Doak Campbell said that curriculum "includes all the knowledge and experience that they can be under the guidance of the school," and the role of the school is discover and develop those personal abilities [4]. Ronald C. Doll (1996) stated: "The curriculum of a school is the formal and informal content and process by which learners gain knowledge and understanding, develop skills, and alter attitudes, appreciations, and values under the auspices of that school"

It can be said that with this concept, the appearance of educational institutions and training institutions (mission, vision, capacity ...) has been clearly reflected in the training products of each University. On the other hand, this concept also shows the autonomy of the educational institution to the curriculum development. Referring to the curriculum, we can find many different classifications based on management decentralization, policy context in each country, the role, degree of autonomy of educational institutions as well as the perspective of approach in curriculum development. Richard S. Peters has argued that [5]. A curriculum is the educational policy proposal on offer by a school or college and is composed of the valued knowledge, values, skills and other dispositions that have been intentionally planned. The curriculum supports both training and education.

For establishments of higher education, Curriculum can be seen as a means of achieving specific educational quality, convey spiritual highlight the "learners are products of the program (Olivia)

Tim Wentling (1993) defines: "The curriculum is the overall blueprint for a training activity. It can be a course over several hours, a day, a week or a few years. The overall design reflects the content of the training, specifying what to expect the learner after finishing the course, it outlines the process of implementing the training content, it also show the training methods and how to evaluate learning results. All the issues of this design is arranged according to a strict schedule" [6] Regarding the concept of curriculum in higher education, there are many views of different authors, but the most shared view is considering an undergraduate curriculum is a formal academic plan for the learning experiences of students in pursuit of a college degree. The term curriculum, broadly defined, includes goals for student learning (skills, knowledge and attitudes); content (the subject 
matter in which learning experiences are embedded); sequence (the order in which concepts are presented); learners; instructional methods and activities; instructional resources (materials and settings); evaluation (methods used to assess student learning as a result of these experiences); and adjustments to teaching and learning processes, based on experience and evaluation [7]. Although the term curriculum is variably used, this definition is sufficiently inclusive and dynamic to account for the many innovations in the undergraduate curriculum that involve instructional methods, sequencing, and assessments as well as instructional goals and content, all of which have been implemented in order to improve learning. During the last decade of the twentieth century, significant changes occurred in Vietnam higher education generally and in the undergraduate curriculum in particular. The employers give feedback about the skills shortage of students after graduation as professional skills, social skills ... led to reduced efficiency and availability of the next workforce. From this fact, many initiatives and reforms of undergraduate curriculum have been proposed reflecting the main changing trends as follows:

(2) The undergraduate curriculum changes from subject-centered approach to capacity-based, learner-centered approach, personalization of learners, promotion of learners' self-directed learning and self-study capacity;

(1) The curriculum ranges from being single in specific disciplines to integrating learning experiences, general and overall competencies in the entire curriculum;

(3) The new evaluation methods provide opportunities to assess and to promote higherorder critical thinking skills and the competencies now valued in higher education;

(4) The undergraduate curriculum is internationalized, from cooperation in curriculum development to the development of output competency standards based on common standards for the regional and world workforce;

(5) The undergraduate curriculum takes into account the priorities to build learners of information technology competencies applied in different career fields to meet the industrial revolution 4.0.

Trends above reflect the diversity and integration of group general capacity of the labor market in the region and the international towards the trend of globalization. This is also a highlight as a matter of priority in curriculum development. In fact, it requires the curriculum development in educational institutions to become one of the professional activities that are regularly, prioritized and respected as an indirect way to improve training quality, create and affirm the position of higher education institutions on the rankings. Curriculum development can be defined as a purposeful, progressive, and systematic process to create positive improvements in the courses offered by a school, college or university. The world changes every day and new discoveries have to be included into the education curricula. Innovative teaching techniques and strategies (such as active learning or blended learning) are constantly being devised in order to improve the student learning experience. As a result, an institution has to have a plan in place for acknowledging these shifts and then be able to implement them in the school curriculum.

If review the process, curriculum development can be found as a process that integrated in the training process, including seven steps:

1. Diagnosis of needs

2. Formulation of objectives

3. Selection of content

4. Organisation of content

5. Selection of learning experiences

6. Organisation of learning experiences

7. Determination of what should be evaluated and the means of evaluation.

Out of these stages in higher education system, the curriculum development and design for the subjects of a course plays central issue of higher education due to the fact that the success and effectiveness of all other steps of the course depends on it. 
On the policy side, the curriculum development in universities now depend on the regulations in each country. With highly autonomous universities, training faculties, member universities are fully responsible for their own curriculum (including curriculum development, curriculum supervising as well as being responsible for the quality of training) based on generally accepted models in the university community and the criteria that accreditation "accreditation associations" (typically universities in the United Kingdom, United States, Australia ...) [8]. The second form is the state management agency in charge of education and training issuing regulations on the curriculum framework (volume and percentage of knowledge sharing among these units in the university training program). Based on that framework, the university develops its own curriculum for students. (in the case of Japan, Thailand, etc.).There are also a number of countries where training institutions are mainly responsible for implementing curricula developed and issued by the State Administration of Education and Training (Myanmar...). As such, it can be seen that the curriculum and curriculum development depend heavily on the degree of autonomy of the universities in each country. On the issue of university autonomy, Author Le Ngoc Hung (2019) "university autonomy can be expressed in two levels: level between universities and state, and level between the university and its units (training faculties, functional departments, autonomy can also be procedural and formal the right to decide on the means, ways to achieve a predetermined goal, or substantial autonomy - the right to decide on the goals and the program of operation [9]. University autonomy is defined as the freedom of an institution to run its own affairs without direction or influence from any level of government. University autonomy is recognized in many different respects and can be generalized as a university's ability to operate in the way it chooses to achieve its mission and goals.
Anderson \& Johnson (1998) state that considering institutional autonomy and the government's role (legal and de facto) vis a vis the institutions' in respect of seven main topics [10]:

- Staff-appointments, promotions and status of academic and senior general staff;

- Students-admissions, progress and discipline;

- Curriculum and teaching-methods, examinations, content, text books;

- Academic standards-degree standards, quality audits, accreditation;

- Research and publication-postgraduate teaching, priorities, freedom to publish;

- Governance-councils, academic boards, student associations;

- Administration and finance-funding of institutions; operating grants, capital and equipment grants, one-off tasks, non-government funding, accountability arrangements.

The General Assembly of UNESCO in the Recommendation concerning the Status of Higher-Education Teaching Personnel gave the following definition [11].

"Autonomy is the institutional form of academic freedom and a necessary precondition to guarantee the proper fulfilment of the functions entrusted to higher-education teaching personnel and institutions".

With the above concepts, it can be seen that the undergraduate curriculum is considered one of the elements of university autonomy, reflecting the degree of academic freedom of higher education institutions that contribute to the realization of the mission and vision of each training institute.

\section{Policy framework of curriculum development}

In Vietnam in the last decade, the trend of autonomy for universities has partly changed in a positive direction marked by the issuance of state management policies to support higher education institutions: 
University Charter, issued under Decision No. 153/2003/QD-TTg by the Prime Minister"; Education Law enacted in July, 2005; Resolution 14 of the Government (14/2005/NQ-CP issued on November 2, 2005) on basic and comprehensive renovation of Vietnam's higher education in the 2006-2020 period; Joint Circular of the Ministry of Education and Training and the Ministry of Home Affairs (July 2009/TTLT-BGDĐT-BNV April 2009) guiding the autonomy and selfresponsibility for task performance, organizational structure, workforce for public units of education and training.

Vietnam National University Hanoi (VNUHN) has been implementing Resolution No. 04-NQ/HNTW by The Fourth Conference of the Party Central Committee (Session VII) on January 14, 1993 on "Building some key national universities", in 1993 the Government issued Decree No. 97/CP on the establishment of Hanoi National University. Decree 97/CP of December 10, 1993 stated that Hanoi National University was given high autonomy, after that, the Government issued Decree 07/2001/ND-CP on Hanoi National University and the Prime Minister signed the Decision. No. 16/2001/QD-TTg, promulgated the Regulation on organization and operation of the Hanoi National University, creating favorable conditions for Hanoi National University to develop with an expanded autonomy mechanism.

Following that policy, Hanoi National University has implemented a decentralization of management in the direction of increasing autonomy and self-responsibility to the social activities of member units and affiliated units. Reasonable management mechanism is completed and promoted effectively: Hanoi National University's units are organized and operate under the mechanism of high autonomy, high social responsibility, opened and inter-connected, promoting the advantage of specialization in the uniform management and coordination of Hanoi National University, incorporating training and scientific research, effective coordination between sectors and fields, using a common staff of scientists (in natural sciences, social sciences and humanities, foreign languages, political theory, national defense education, physical education...) and material and technical facilities (laboratories, libraries, dormitories, gyms, yards, information technology infrastructure ...) of Hanoi National University. Such a structure of Hanoi National University allows the units to proactively focus their resources for building a contingent of cadres, facilities ... related to their training specialty and specific research fields. One of the contents reflecting the trend of academic autonomy at the National University is the curriculum and curriculum development. In order to support the development curriculum in accordance with the defined mission and vision, in addition to the general regulations of the Government and the ministries, boards and branches of Hanoi National University also issued many other documents to do bases for the development, update and adjustment of the training program in general, including the bachelor training system (specifically as follows: Training regulations at Hanoi National University issued together with Decision No. 5115/QD-DHQGHN dated December 25, 2014 of Hanoi National University President; Decision No. 1366/QDDHQGHN dated April 25, 2012 of VNU President On issuing the Regulation on opening and adjusting the curriculum at Hanoi National University; Circular No. 32/2013/TT-BGDDT on August 5, 2013 by the Minister of Education and Training amending and supplementing the List of Level IV education and training at college and university levels; the general spirit reflected in the above policies emphasizes the principles of curriculum development in an approach to learner competencies linked to the social needs and general context of the region, and appropriate to the mission and strategy of Hanoi National University, ensuring the quality of training and promoting the effectiveness of international cooperation. 
As a member unit of Hanoi National University, the University of Education has declared its philosophy and educational goals towards the learner, for the interest of the learner, that is "the Educational philosophy of the university is humanistic and liberal, aiming at the goal of education is to train learners with mature personalities, strong professional knowledge and job skills, professional spirit, conscientious attitude and creativity in the work", in order to carry out the Mission "University of Education, Hanoi National University is a high-quality higher education and research institution in education science and technology, applied for training teachers, managers and other human resources in the field of education".

To accomplish this Mission, the University of Education focuses on developing training programs including updating six traditional teacher bachelor training programs (Mathematics, Physics, Chemistry, Biology, Literature and History), and quickly developed six new bachelor degree programs. New fields are School Administration, Educational Technology Administration, Education Quality Management, School Counseling, Science Education and Natural Science Education. Along with that the school will also continue to curriculum development like preschool; primary education ... to implement training to catch up with the social needs and general trends of the education sector. Besides, complying with the requirements of Hanoi National University in the development of double degree training programs with other university members of Hanoi National University such as University of foreign languages and international studies, University of business administration, etc. This is considered as an attractive and beneficial point, a competitive advantage to attract learners, but the development of training programs requires the coordination of two disciplines, two specialized departments are quite complex in agreement on the design and distribution of program content.

\section{Methods}

In order to clarify the above two research questions, we conducted a survey of the current situation of training program development at the University of Education.

Objects and research methods

- Objective of the research: We conducted an investigation on 41 lecturers of the Faculty of Education, Educational Technology, Quality Management and Education Management at the University of Education, Hanoi National University.

- Research methodology: The research method used in this research is the survey by questionnaire, interview, data processed by mathematical statistics.

To assess the curriculum development in the current context of university autonomy implementation at the University of Education, we developed a survey form based on Circular 04/2016/TT-BGDĐT which comprises requirements to assess the quality of training programs at all levels of higher education in order to assess the effectiveness level of the current training program of the university compared to the standard. In addition, we also evaluate the forms of curriculum development and the degree of autonomy of the current curriculum development at the University of Education. Each content is assessed at 5 levels:

- Regarding the form of curriculum development (1/not totally, 2/confused, 3/sometimes, 4/often, 5/very often);

- Regarding the degree of autonomy of the curriculum development (1/very low, 2/low, 3/medium, 4/fair, 5/high);

- Regarding the effectiveness of the curriculum development (1/very ineffective, 2/ineffective, 3/effective, 4/quite effective, $5 /$ very effective).

Each level is assessed on a scale of 1-2-3-45 , with 5 levels as follows: 
+ Level $1: \mathrm{X}=1 \div 1.8$

+ Level $2: X=1.8 \div 2.59$

+ Level 3: $X=2.60 \div 3.39$

+ Level 4: $X=3.40 \div 4.19$

+ Level 5: $\mathrm{X}=4.20 \div 5.00$

\section{Findings and discussion}

\subsection{Forms of curriculum development at the University of Education}

In the survey, we found that at the University of Education (University of Education), the training departments have used all 4 forms of developing popular curriculum development in higher education institutions (3/4 at often; $1 / 4$ at an irregular level) in which the curriculum development is the task of lecturers and managers ... in schools, after which they often exchange and consult with each other inside and outside the school $(3,59)$; curriculum development with wide decentralization is the task of both lecturers and the opinions of alumni, employers (3.49) ... This result reflects the advantages of the University of Education in steps to mobilize and connect forces related to training activities, enhance international cooperation ability while still relying mainly on teaching staff, scientists inside the university as pillars in professional aspect. The University of Education as well as other members of the Hanoi National University has taken modern approaches to the international trend in curriculum development. The cooperation in the curriculum development at the University of Education shows that the curriculums are always in reference with equivalent curriculum at prestigious universities, which are highly ranked in the world, in the regular consultation by international experts. On the other hand, the voice of alumni and employers is always valuable information for any stage of the curriculum development process.
Table 1. Types of curriculum development at the University of Education

\begin{tabular}{lll}
\hline TT & Types of Curriculum Development & $\mathrm{M}(N=41)$ \\
\hline 1 & $\begin{array}{l}\text { Expert- centered curriculum } \\
\text { development, decisive experts, } \\
\text { lecturers, managers, etc. are } \\
\text { executors. }\end{array}$ & 3.22 \\
2 & $\begin{array}{l}\text { Curriculum development through } \\
\text { consultation with specialists, } \\
\text { Lecturers, managers ... have a direct } \\
\text { decision role but they still need } \\
\text { advice from experts }\end{array}$ & 3.44 \\
& $\begin{array}{l}\text { Curriculum development through } \\
\text { consultation with specialists. The } \\
\text { curriculum development is the task } \\
\text { of lecturers and managers ... in } \\
\text { schools, after which they often } \\
\text { exchange and consult with each } \\
\text { other inside and outside the school } \\
\text { The negotiated curriculum, } \\
\text { curriculum development with wide } \\
\text { decentralization is the task of both } \\
\text { lecturers and the opinions of } \\
\text { alumni, employers }\end{array}$ & \\
\hline Mean & 3.59 \\
\hline
\end{tabular}

Talking about this content, a group of lecturers at the Faculty of Education Management in charge of curriculum development said: "We have actively consulted with international scientists at experienced universities such as Waikato University; University of Birmingham ... their consultants also support us a lot to develop an up-to-date and modern curriculum. That is really beneficial for learners". However, there are also concerns regarding the implementation of these types of consultations due to constraints of financial resources and international networks of relations and cooperation.

5.2. The degree of autonomy in curriculum development at the University of Education.

Assessment of the autonomy in curriculum development at the University of Education is presented at 9 contents associated with the entire design and implementation of curriculum development (including both new construction and regular adjustment of curriculum )

The results show that the curriculum development is quite autonomy (M: 3.73-4.07). 
The two highest-rated autonomy contents are curriculum development assigned to the responsible subject department/training faculty according to the prescribed curriculum framework (4.05) and the Faculty of Training proactively compilies and builds, assesses curriculum, materials and other resources for teaching (4.07). This shows that the subject deparment and the faculty are considered as basic units of expertise demonstrating the academic autonomy in curriculum development.

Mr. N.D.H - Vice-Rector, said "implementing the policy of Hanoi National University and encouraging the trend of academic freedom, at the University of Education, professional activities in general and the curriculum developmentin particular entrust the training faculties with autonomy, specifically from proposing and developing a new curriculum to meet social needs to activities such as compiling textbooks, documents and other resources for teaching activities. The curriculum development has always been consulted by universities with high ratings in training that subject".

From the perspective of training faculty, Mr. N.C.T - Head of Pedagogy Faculty, assessed the $a+b$ training model of Hanoi National University, besides many advantages, there are also so many difficulties in curriculum development (especially for the fields which two faculties or two Universities have) requires the sharing of expertise and the level of cooperation among the stakeholders. Currently, implementing the requirements of Hanoi National University in parallel training, considering this as an attractive point, a competitive advantage to attract learners, the curriculum development requires the coordination of two subject deparments, two faculties in charge specialization which are quite complicated in unifying the design and distribution of program content.

In particular, the decentralization of setting up standards for lecturers and recruiting lecturers to the units (3.73) and training faculty, the lecturers in charge of the subject actively import specialized textbooks from advanced schools and countries in the world to teach, and must be solely responsible for the content of the textbooks, materials (3.78) are assessed not to achieve high autonomy. As guidelines, the training faculty and subject department can be proactive in exploiting and finding learning resources for the subject. However, in reality, the budget for this activity is completely incomplete, the faculty in the situiation of quality requirements, still has enough textbooks as well as references. Each training department and subject group must now manage in different ways. Ms. D.H.Y said that: when developing a new curriculum, our faculty must mobilize individuals in the department and external experts to participate in writing the textbooks. The printing cost is entirely from the instructor's pocket, not find out from any other source of support. The need is still in need to be done because the curriculum is vital for each discipline but it is also necessary to encourage faculty members to write books and cover their own expenses. As mentioned in the analysis of curriculum development forms, the current main form is still entirely based on staff so the competency role of staff (including capacity of curriculum development is very important). It is essential for the faculty to be autonomous in recruiting and developing faculty. This is also the common opinion of many managers in other faculties when discussing about this content.

Table 2. The degree of autonomy in curriculum development

\begin{tabular}{lll}
\hline TT & $\begin{array}{l}\text { The degree of Autonomy in } \\
\text { Curriculum Development }\end{array}$ & $\begin{array}{l}\text { M } \\
(\mathrm{n}=41)\end{array}$ \\
\hline \multicolumn{3}{c}{$\begin{array}{l}\text { Develop the curriculum assigned to } \\
\text { the responsible subject department }\end{array}$} \\
$\quad \begin{array}{l}\text { / training faculty according to the } \\
\text { prescribed program framework }\end{array}$ & 4.05 \\
2 & $\begin{array}{l}\text { Decentralize the development of } \\
\text { standards for lecturers and recruiting } \\
\text { lecturers at member units }\end{array}$ & 3.73 \\
& $\begin{array}{l}\text { To develop curriculum according } \\
\text { to the prescribed curriculum } \\
\text { framework on the basis of } \\
\text { professional strengths of each } \\
\text { training faculty and university. }\end{array}$ \\
\hline
\end{tabular}




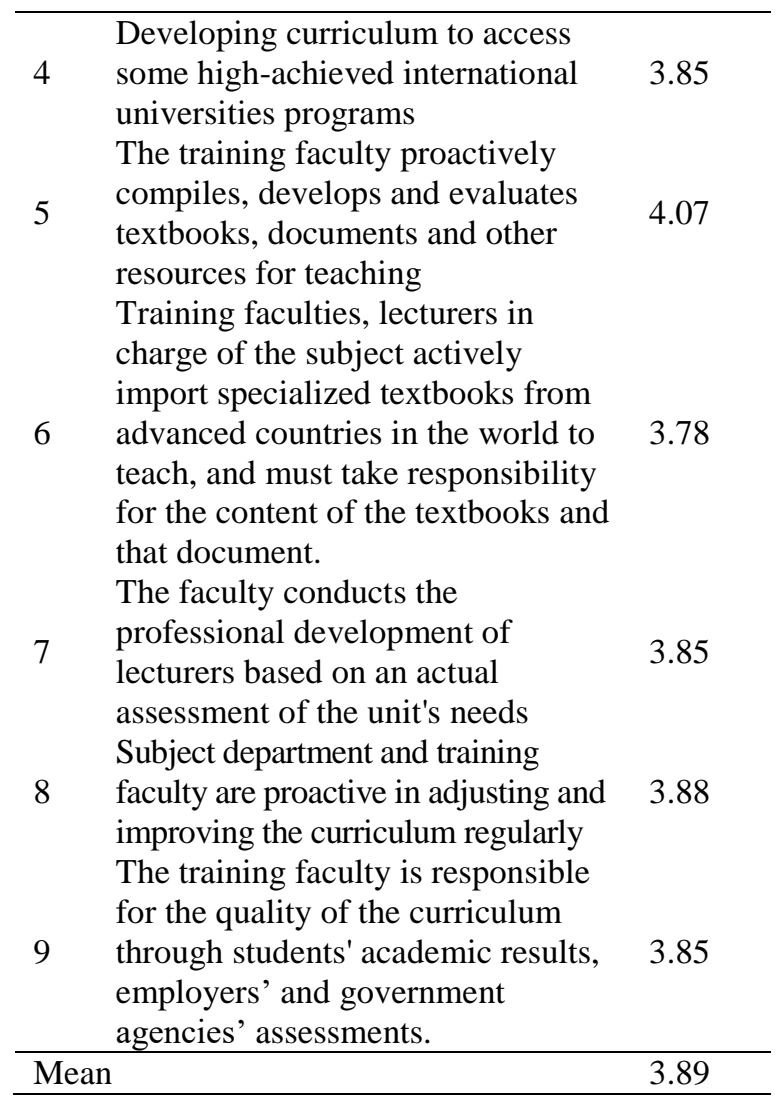
5.3. The effectiveness of the curriculum at the
University of Education

Based on the 10 curriculum evaluation criteria according to Circular 04/2016/TTBGDDT we have evaluated each detailed content. The current curriculum at the University of Education is at a fairly good level (none of the content is good). Strengths are buliding objectives and output standards of undergraduate curriculum as well as the structure and content of the curriculum (4.07 and 3.99). The content that reaches the lower level than the 10 contents assessed are the support staff (3.51); improve the quality (3.62).

Table 3. The effective level of curriculum at University of Education

\begin{tabular}{lll}
\hline TT & $\begin{array}{l}\text { Criteria for evaluating the } \\
\text { effectiveness level }\end{array}$ & $\begin{array}{l}\text { M } \\
(\mathrm{n}=41)\end{array}$ \\
\hline 1 & $\begin{array}{l}\text { Objectives and output } \\
\text { standards of the curriculum }\end{array}$ & 4.07 \\
2 & Description of the curriculum & 3.99 \\
\hline
\end{tabular}

\begin{tabular}{lll}
\hline 3 & $\begin{array}{l}\text { Structure and content of the } \\
\text { curriculum }\end{array}$ & 4.07 \\
4 & $\begin{array}{l}\text { Approach in teaching and } \\
\text { learning }\end{array}$ & 3.66 \\
5 & $\begin{array}{l}\text { Evaluate learning outcomes of } \\
\text { learners }\end{array}$ & 3.82 \\
6 & Faculty, researchers & 3.74 \\
7 & Staff & 3.51 \\
8 & Learners and activities that & 3.75 \\
9 & support learners & 3.66 \\
10 & Facilities and equipment & 3.62 \\
\hline Mean & 3.75 \\
\hline
\end{tabular}

- Objectives and output standards of the curriculum

For the curriculum, the curriculum 's objectives and standards are determined in the form of a matrix with linking each module in the knowledge blocks with specific competencies, qualities and skills with the differentiation and intergration which reflect the needs of the domestic labor market and gradually meet international standards. The determination of output standards for each discipline in each training department can be done in different forms, ensuring principles and feasibility in real conditions.

- Description of the curriculum

The curriculum of the University of Education is always fully and publicly updated on the official Web site to provide information to learners and community. This is considered a mandatory requirement for all current curriculum of the University of Education.

- Structure and content of the curriculum

With 3 contents evaluating the effectiveness of the curriculum at the University of Education including the objectives and output standards of the curriculum (4.07), curriculum description (3.99), The structure and content of the curriculum (4.07) are evaluated to perform the best, showing that the departments, faculties and lecturers have done well in agreement with the objectives and standards of outputs, the structure and content of the program are seamlessly designed and supplemented intergratedly (shown in the output standard matrix). Each content of knowledge and 
modules in the program is associated with specific competencies, qualities and skills at each level.

Mr. N.C.T said that: In our facutlty, with each curriculum, there were established professional groups and teams. Such collaborative activities help to share professional perspectives and have an overview of the curriculum in the most beneficial way for learners.

- Approach in teaching and learning

This content is considered to be quite effective (3.66), showing that, in general, the departments, faculties and lecturers have shown the strength of the University of Education in Hanoi National University with deep expertise in teaching methodology. Besides, fostering and self-fostering activities also helped the teaching staff develop their competencies in teaching activities. However, difficulties in class and facilities planning also hinder the implementation of active teaching methods, especially skills training and differentiated teaching.

Ms. N.T.L stated: My class has more than 54 students but the classroom is quite narrow, the organization of discussion, group work is quite difficult. In addition, the level of approaching individual students to support them is also very difficult for me.

- Evaluate learning outcomes of learners

According to the current regulations on examination and evaluation of students' learning results, the level of implementing this content at the University of Education is quite good (3.82). The forms of tests and assessments are proposed by the lecturer and approved by the Faculty. But via discussion, we also get some current comments such as the tools, software to support the test and the evaluation did not meet the needs of lecturers and students, feedback on results of assessments have not been regularly updated, no time for teachers to exchange, and evaluating each individual student has not been implemented, and help learners approach promptly to improve learning activities.

- Faculty, researchers, staff
In recent years, the attraction and recruitment of experienced lecturers and researchers has contributed to improving the status of the University of Education in general. This team has continued to accompany the university in carrying out its mission in the new period (3.74).

However, through observation and discussion, we realize that the work design is not really reasonable with the lack of policy mechanisms, objective assessment tools to recognize the contribution and encourage achievements of the staff, lecturers in the unversity resulting in not promoting the total effectiveness of individuals and collectives.

For the staff, the evaluation result was 3.48 , the lowest among 9 contents. This result may be due to streamlining of staff, instability and inadequate fostering and self-fostering activities, not really meeting the needs of staff, leading to the professional skills of this team are not as expected.

In addition, the regulations on the incomplete coordination mechanism between the training department and departments also cause non-functional conflicts that significantly affect the development of training programs at university.

- Learners and activities that support learners

Learner-centered teaching has been evident in most educational activities in general at the University of Education, from the stage of admissions counseling to the end of the course. Learners have access to information, support facilities and regular academic counseling activities. In the context of limited revenue, Ued still takes advantage of resources to raise scholarships to encourage students with good academic achievements, invest in beautifying the learning space as well as building the university's of friendly and opened culture.

The results of the assessment of student support at university mainly focused on the good and good level is a good signal. However, all of these 5 contents have a low level of expression, and the level of very good is not high (about less than 20\%). This shows that the university needs to pay attention to the faculty, 
staff and regulations; facilities of the university should be invested more professionally so that the results of supporting learners is more evenly.

- Facilities and equipment

The results show that the condition of facilities and equipment for program development is assessed at a fairly good level (3.61-3.76). In particular, the content The system of working rooms, classrooms and functional rooms with appropriate equipment to support training and research activities is rated lower than other contents (3.61).

As discussed by Mr. Nguyen, Duc Huy Vice-Rector of the Ued: Along with other priorities for learners, the University of Education has made significant investments in facilities, teaching equipment to support teaching activities. The classrooms are equipped with appliances, equipment and regular maintenance, many specialized laboratories and classrooms have also been newly invested. However, the introduction of new disciplines and the increase in the number of learners at all levels also create significant pressure on the implementation of training programs with efficiency and quality.

- Improve the quality

Feedback from stakeholders regarding training programs (social needs, employers' assessments and learners' etc.) and the regular improvement of training program are two highlights of the content of improving quality for training program.

The survey results show that this is half of the lowest rated content (3.59), in which there are 02 indicators rated the lowest among 58 indicators, they are Quality of support services and facilities (libraries, laboratories, IT systems and other support services) are evaluated and improved (3.44) and Feedback mechanism of stakeholders system, evaluated and improved (3.34).

Understanding the causes of the evaluation results, Ms. P.T.H - a lecturer said: we have regular program improvements periodically and recorded feedback from learners at any of these stages of the training process. The updated content, new materials, and new information are always verified and included in the teaching to ensure the subjects and disciplines are topical.

However, many lecturers also acknowledge that this depends on the individual competence of each teacher. The ineffective promotion of the subject deparment's role has led to inefficient collective activities. In addition, the current assessment tool is quite general, lackluster, not specific; regular assessment has not really become a cultural part in university administration and has no effect on quality management of the university in general.

With the research results presented above, we believe that the curriculum and curriculum development at the University of EducationHanoi National University has had encouraging results especially in the context of modern autonomy now. Given this situation, we propose a number of solutions to curriculum development at the University of Education to contribute to the overall training quality of Hanoi National University.

\section{Solutions}

Fostering program development capacity

- Implementing to foster the capacity of curriculum development for lecturers who directly teach;

- Fostering management skills of curriculum for officials in charge of training service.

Promote cooperative activities in curriculum development

- Cooperation in curriculum development activities; Firstly, between lecturers of majors, groups, faculties and between university members of Hanoi National University so that the programs can be flexible in using the A $+\mathrm{B}$ training model to help learners with an opportunity for transition study and transformation within the University of Education and Hanoi National University;

- Cooperation and democratization in the curriculum development with the participation of alumni, students, employers and experts of training to help the curriculum development at the university to be developed based on learners 
"learning experiences, employers" assessments and social needs.

- Cooperating with foreign experts in curriculum development, inheriting the advantages of successful curriculum in the world.

Step by step internationalization of curriculum development

- Regularly updating professional skills standards in the ASEAN region and the world for job placements related to the university's training majors for reference in curriculum development:

- Establishing the curriculum's objectives and output standards to meet learners' expectations and characteristics of the world and regional context;

- Focusing on including useful, practical and most beneficial knowledge and skills for the development of learners' capacity as well as timely and regular response to the needs of the times.

Diversify curriculum

- Developing diverse curriculum in the direction of research and application in the direction of differentiation, meeting learners' needs;

- Developing open and flexible curriculum taken into account specific characteristics in each locality.

Strengthen and perfect the school culture

- Communicating the school's mission, vision, strengthening and perfecting the school culture to each individual participating in training activities in general, curriculum in particular, attaching importance to such factors as a part of the "hidden training" curriculum that makes up the university's identity and value.

\section{Conclusion}

With the above research results, it can be seen that the forms of curriculum development at the University of Education are diversified, showing the cooperation and mobilization of lecturers and researchers on and off campus to join as well as the voices of the parties involved in the curriculum. The level of autonomy of this activity is quite good, reflecting the joint efforts of the University of Education as a member unit of Hanoi National University as well as attaching importance to academic freedom. Based on the evaluation criteria, the current curriculum of bachelor degree are relatively effective with the advantages and limitations reflected. The above results are the basis for our research team to propose solutions. We view this research as an assessment in the contribution to the quality management of education at the University of Education as well as the implementation of the development strategy of Hanoi National University in the coming period.

\section{References}

[1] D. Pratt, Curriculum planning: A handbook for professionals, Fort Worth: Harcourt Brace College Publishers, 1994.

[2] W. Pinar, Currere, In C. Kridel (Ed.), Encyclopedia of curriculum studies, Thousand Oaks, CA: Sage, 2010, pp. 177-178.

[3] F. Bobbitt, The Curriculum, Boston, MA: Houghton Mifflin, 1918.

[4] L. Brady, Curriculum development, Sydney: Prentice Hall, 1995.

[5] Peters, (Richards, J. C. (2001), Curriculum development in language teaching: Cambridge University Press, 1966.

[6] L. Tim, Wentling, Guide to Curriculum Development, FAO, 1993.

[7] Nguyen Duc Chinh, Education Development, Education Publishers of Vietnam, 2017.

[8] Lam, Quang Thiep, Undergraduate Curriculum Development (cdsonla.edu.vn/daotao).

[9] Le Ngoc Hung, University autonomy: concept and education policy in Vietnam, Journal of Political Theory. http://www.vanhoahoc.vn/nghiencuu/van-hoa-hoc-ung-dung/van-hoa-giao-duckhoa-hoc/3609-le-ngoc-hung-tu-chu-dai-hockhai-niem-va-chinh-sach-giao-duc-o-vietnam.html/, 2019.

[10] D. Anderson, R. Johnson, University Autonomy in Twenty Countries, Department of Employment, Education, Training and Youth Affairs, Canberra

[11] http://portal.unesco.org/en/ev.php-

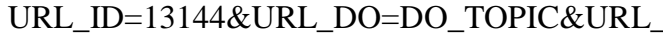
SECTION=201.html. 